\title{
The Development of New Energy Car Rental Business in China
}

\author{
Yuting Qian \\ College of Economic and Management \\ North China Electric Power University \\ Beijing, China
}

\begin{abstract}
At present, the sharing economy is booming based on the basic contradiction between the growing good living needs of our people and the uneven development of unbalanced development. As the representative of the sharing economy, the new energy vehicle sharing leasing project not only facilitates people's travel, but also improves the utilization of social resources and promotes the improvement of environmental problems. Based on the result of questionnaire survey, this article collects relevant statistics and analyzes the implementation of domestic new energy automobile lease project, points out the current problems of new energy automobile lease project development and offers some appropriate suggestions.
\end{abstract}

Keywords-Sharing Economy; new energy vehicle leasing; domestic

\section{INTRODUCTION}

The idea of car-sharing was first proposed by Zurich Cooperative in Switzerland in 1948. Zurich Cooperative is well-known as established the world's first automobile cooperative. [1]Car-sharing is a brand-new way of car rental, which came into being under the thinking of "Not for the ownership, but for the utilization”[2]. By the development of technology, the majority of cars used in terms of car-sharing have been translated from the traditional petroleum-based car into hybrid electric vehicle or even new energy vehicle. In China, the earliest company which opened up car-sharing business is Che Fen Xiang. Che Fen Xiang established in Hangzhou City in 2010, offering service for staffs work in Alibaba Group. Currently in Beijing, Shanghai, Hangzhou, Shenzhen, Changsha, Wuhan and other first and second-tier cities running a car-sharing rental business.

In recent years, the service of car-sharing rental business is spreading to other cities regardless the cities mentioned above and having a more and more broad mass base[6]. In the current stage, Shanghai EVCARD rental business model has become the largest electric car time-sharing rental platform in China[1]. New energy vehicles time-sharing leasing project in our country has a bright future. However, a series of problems also encountered in the promotion process.

Aiming at the related problems, we designed a questionnaire to understand people's use of new energy vehicle's time sharing lease from age, occupation and region. Meanwhile, we investigated the factors that affect people's use of the product and their views. We send out the recycling questionnaires on the platform and organize the data as follows

\section{ThE RESUlts OF QUESTIONNAIRE}

\section{A. The background of survey}

The rental market of car-sharing is becoming mature over time so that more and more pure electric vehicles which are short-distance or middle-distance driving range are going into the market. Along with the innovation and maturity of the internet, car-using smart terminal, and online payment etc., a great number of operators joined the battle of market competition. Operators consist of vehicle manufacturers which take advantage of online application services, traditional rental companies which are under up-grading transformation, and also, new participants who come from emerging fields such as the Internet. Nowadays, there are more than 100 car-sharing rental companies all over China, and more than 50,000 available cars in total. Due to the great support from national policy, the relatively low cost, and simple operation of cars, university campus become one of the earliest sites of new energy car rental business.

\section{B. The purposes of survey}

Through questionnaires, we hope that we can figure out the general public's point of view on the new energy vehicles time-sharing rental projects. Additionally, by doing data-based analysis, we want to sum up the current problems and make recommendations toward Chinese car-sharing economy.

\section{Methodology}

We used WenJuanXing website and distributed by snowball sampling. By the end of this survey, we received 237 effective questionnaires. In consideration of the distribution of major car-sharing economy that mostly further develop in Beijing-Tianjin-Hebei region and the Yangtze River Delta region, $56.12 \%$ of our participants are from Beijing-Tianjin-Hebei region, 27.85\% of whole participants are from the Yangtze River Delta region. Among them, 35.02\% are male, and $64.98 \%$ are female. We took age as one available element and tried to make age distribution as balanced as possible. The proportion of students (18-25 years old) is $35.44 \%$. There are two age groups of people who are working currently, $26-45$ years old people take $38.83 \%$ and $46-60$ years old people take $24.47 \%$. Nevertheless, we were not able to get enough participants form retired staff (over 60 years old), only $1.27 \%$ among all participants. 


\section{Data analysis}

a) New energy car-sharing rental business as a new concept is not fully understood and accepted by most of the people.

In our participants, only $6.75 \%$ of them showed a very well understanding of new energy car-sharing. On the other hand, $42.19 \%$ of participants do not know at all or only heard of it, and $50.05 \%$ of participants only know some basic information.

b) New energy car-sharing rental business concentrates in Beijing-Tianjin-Hebei region and the Yangtze River Delta region currently.

TABLE I. HAVE YOU EVER HAD AN EXPERIENCE IN LEASING AN ELECTRIC CAR

\begin{tabular}{|c|c|c|c|c|}
\hline & A & B & C & $\mathrm{D}$ \\
\hline Beijing,Tianjin, Hebei & $3.76 \%$ & $28.57 \%$ & $65.41 \%$ & $2.26 \%$ \\
\hline $\begin{array}{c}\text { Yangtze River Delta } \\
\text { region }\end{array}$ & $6.06 \%$ & $28.79 \%$ & $63.64 \%$ & $1.52 \%$ \\
\hline $\begin{array}{l}\text { Pearl River Delta } \\
\text { region }\end{array}$ & $9.09 \%$ & $9.09 \%$ & $81.82 \%$ & 0 \\
\hline Other areas & $11.11 \%$ & $40.74 \%$ & $44.44 \%$ & $3.70 \%$ \\
\hline
\end{tabular}

According to the distribution map, China's current major new energy car-sharing rental business locate in Beijing-Tianjin-Hebei and the Yangtze River Delta region, therefore, the use of these two regions is relatively frequent. The rapid economic development is conducive to the promotion of new energy car-sharing projects.

a) New energy car-sharing has a variant usage and strong market prospects.

Most of our participants (47.68\%) choose to do a car-sharing rental for short term trips, while $31.22 \%$ of respondents said they would commute by the way of car-share.

b) The development of car-sharing business still has many obstacles.

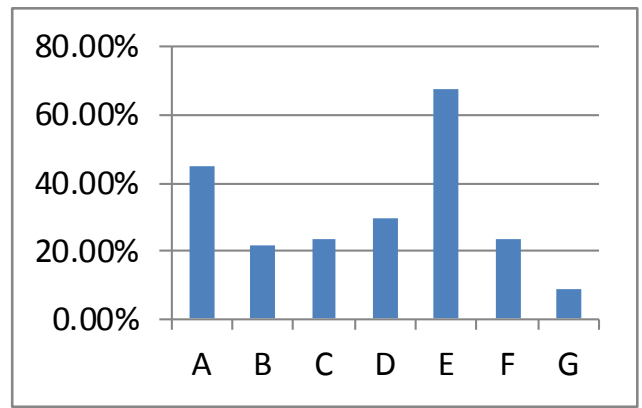

A: Have private car

B: Not as convenient as a taxi

C: Less type of vehicle

D: High price

$\mathrm{E}$ : Inconvenient charging

F: Less understanding

G: Other

Fig. 1. Factors that prevent people from hiring new energy cars

According to the questionnaire, the growing popularity of private cars is one of the biggest obstacles to the development of car-sharing projects for new energy vehicles. Results show that private car owners rarely choose car-sharing as one way of transportation. Moreover, participants who plan to buy a private car coming out a tendency of avoiding using car-sharing. Low charging pile penetration, is another limiting factor of the development of new energy car-sharing rental business. The respondents said they would like to use public bicycles rather than new energy cars. Bicycle-sharing is the alternative way of car-sharing on their perspective. Not only due to its lower price, but also the extra function of doing exercise. In addition, few categories of car to choose from, expensive leasing prices, the use of barriers and other issues have hindered the booming of new energy car-sharing rental projects as well.

c) The public has great expectations for the prospect of new energy car-sharing business

Most of our participants showed an optimistic attitude and held a high expectation in terms of the question that "What do you think of new energy car-sharing rental business". Many of them realized that the development of this project is a possible way of solving the problem, which is the huge difficulty of purchasing private cars in big cities. At the same time, using a large quantity of new energy vehicles to replace traditional vehicles using fuel as the main driving force can ease air pollution to a certain extent. The distribution of charging piles has become one of the most concerned issues for the public. The inconvenience of charging pile has hindered the public's desire of using new energy vehicles. The questionnaire also revealed that some enterprises only set charging points in certain responsible area in order to attract members, but did not place new energy vehicles on time, which is a cheating behavior to people, own the membership of the company, and greatly undermine the reliability of the company.

\section{THE CONCLUSION OF THE SHORTCOMING OF CAR-SHARING}

a) The degree of economic prosperity or become a key factor in the new energy car-sharing rental projects. Relatively economic prosperous cities are more densely populated and have a better public transportation system, which led to an increase of the demand for car-sharing rental business. At the same time, the vigorous implementation of the car-sharing rental project of new energy vehicles in big cities can lighten the pressure of purchasing a private car and can ease the atmospheric environment and traffic pressure in a degree.

b) The traditional way of thinking is one of resist elements of new energy vehicles. People's contradiction and exclusion of new things to some extent hindered the promotion of new energy car-sharing rental projects. Comparing with the situation that public bicycle is facing the problem of private occupation, enterprises which willing to promote the new energy car-sharing rental projects are likely to be difficult to maintain a certain profit or even threaten the healthy business running.

c) Distribution of outlets and charging pile. The high cost of car-picking outlets and charging pile, scattered distribution are two of the issues in project promotion. The inconvenience of parking and the necessity of charging force people to dispel the idea of using the project. 
d) Government regulation needs to be improved. In order to support the car-sharing rental project of new energy vehicles, the Chinese government has released a series of subsidy support programs. However, as the result of the chaotic market of new energy vehicles, there are some enterprises under the banner of new energy vehicles cheat to get loans and subsidies from the government. They not just contribute nothing to the actual development of the project, but on the other hand, they harmed the interests of other honest enterprises.

\section{POLICY RECOMMENDATION AND SUGGESTIONS}

a) New energy car-sharing rental business can do some pilot experiences in some big cities at first. After obtaining sufficient experience and lessons, it can be promoted to other cities.

b) Charging pile arrangement can be combined with the development of the private electric vehicle in recent years in China. Enterprises can jointly build a charging network with the government, which not only reduces the high cost of each enterprise building their own charging network, but also can make the charging network cover more areas. At the same time, the investment in public utilities can enhance the reputation of enterprises and benefit themselves in a long-term[3].

c) Government and social communities can publicize the superiority of new energy car-sharing rental business by advertisement or other activities, to reduce the resist emotions from the public toward the project. For example, time-limited free experience activities, which are a good chance to introduce this business to the public to, allowing them to fully experience the convenience of the project.

d) Government should draw to the following system of regulatory review and supervision, fixing the original imperfect measures of government subsidies, reform or eliminate unqualified business [4]. In addition, the government can follow the procedure of European countries, focusing on subsidies to make new energy vehicles and charging pile construction business breakthroughs.

\section{Conclusions}

The development of the new energy vehicle time sharing leasing project is the trend of the times. It is the need of sustainable development and the need of the construction of ecological civilization. China should seize this opportunity, increase support for the project, learn from experience and lessons, improve technology and innovate, so as to promote the transformation and upgrading of China's automobile industry.

\section{REFERENCE}

[1] Weidong Chen, Ruoyu Yang, Haobo Yang. Research on the current situation, problems and Countermeasures of the development of new energy car rental in China -- Taking the "EVCARD" model of Shanghai as an example[J]. Integrated transport, 2017 (8) :89-92

[2] Xiaohong Yang. The current situation, problems and Countermeasures of the joint development of new energy rental car and time sharing lease[J]. China International Finance and Economics (Chinese and English), 2017 (21)

[3] Wenjin Wu, Research on development path and policy of new energy vehicles in China under low carbon economy [M].Beijing: Economic Science Press, 2014.10:20-35 (In Chinese)

[4] Weibo Zhao, Dong xiao Niu. Research on the promotion strategy of time sharing lease for electric vehicles[J]. Science and technology and Industry, 2017,17 (4) :111-116

[5] Car rental platform "enjoy a lot of cars". http://kuailiyu.cyzone.cn/article/5156.html

[6] Wenda Wu. Research on car sharing model and its market analysis in China[D].Guangzhou: Sun Yat-sen University, 2010 